\title{
Universiteit
}

Leiden

The Netherlands

\section{Public leaders' organizational learning orientations in the wake of a crisis and the role of public service motivation}

Broekema, W.G.; Porth, J.; Steen, T.P.S.; Torenvlied, R.

\section{Citation}

Broekema, W. G., Porth, J., Steen, T. P. S., \& Torenvlied, R. (2018). Public leaders' organizational learning orientations in the wake of a crisis and the role of public service motivation. Safety Science, 113, 200-209. doi:10.1016/j.ssci.2018.11.002

Version: $\quad$ Publisher's Version

License: $\quad$ Licensed under Article 25fa Copyright Act/Law (Amendment Taverne)

Downloaded from: https://hdl.handle.net/1887/3250036

Note: To cite this publication please use the final published version (if applicable). 


\title{
Public leaders' organizational learning orientations in the wake of a crisis and the role of public service motivation
}

\author{
Wout Broekema ${ }^{\mathrm{a}, *}$, Jan Porth $^{\mathrm{b}}$, Trui Steen ${ }^{\mathrm{c}}$, René Torenvlied ${ }^{\mathrm{d}}$ \\ ${ }^{\mathrm{a}}$ Institute of Security and Global Affairs, Leiden University, Netherlands \\ ${ }^{\mathrm{b}}$ Institute of Public Administration, Leiden University, Netherlands \\ ${ }^{\mathrm{c}} \mathrm{KU}$ Leuven Public Governance Institute, KU Leuven, Belgium \\ ${ }^{\mathrm{d}}$ Institute of Public Administration, University of Twente, Netherlands
}

\section{A R T I C L E I N F O}

\section{Keywords:}

Crisis leadership

Crisis management

Organizational learning

Crisis learning

Public service motivation

Mayors

Survey

\begin{abstract}
A B S T R A C T
This study explores public leaders' organizational learning orientation in the wake of a crisis. More precisely, we study the association between public leaders' public service motivation and their learning orientation (instrumental versus political). This research addresses the lack of systematic empirical data on crisis-induced learning and provides a first systematic operationalization of this important concept. We analyze survey data collected from 209 Dutch mayors on their learning priorities in responding to a hypothetical crisis situation in their municipality. The mayors' response patterns reveal (1) "cognitive", (2) "behavioral", (3) "accountability", and (4) "external communication" dimensions of crisis-induced learning. We find that mayors with a stronger public service motivation put more effort into instrumental learning (dimensions 1 and 2), and surprisingly, also into political learning (dimensions 3 and 4). Mayoral experience in previous crises is positively associated with accountability-related learning after a crisis. However, mayoral tenure is negatively associated with crisis-induced behavioral learning.
\end{abstract}

\section{Introduction}

Public leadership plays a central role in crisis management. In the wake of a crisis, public leaders are confronted with highly complex and challenging tasks. They have to engage in a variety of pressing activities at the same time (Boin and 't Hart, 2003; Boin et al., 2016). One of the core crisis management challenges facing leaders is to foster organizational learning (Boin et al., 2008). Learning is a crucial process in achieving an adequate crisis response, a proper return to normality, and preventing future crises or, in other words, in creating a resilient organization. Thus, when under the strong political and media pressures brought about by a crisis, public leaders have to decide quickly which crisis-related learning activities to prioritize.

On the one hand, public leaders need to put effort into instrumental learning: to develop deeper knowledge and understanding of the causes of the crisis and, where appropriate, adapt organizational aspects such as culture accordingly (Fiol and Lyles, 1985; Huber, 1991; Turner, 1976). On the other hand, public leaders are also occupied with political learning: refining their political crisis management strategy, allocating blame, limiting reputational damage, and improving the organization's external communications (Boin et al., 2008; Birkland, 2006; May,
1992). In this paper, we explore the structural patterns in the organizational learning orientations of public leaders in the wake of a crisis, and seek an initial explanation for the differences in these orientations.

There have been a considerable number of studies on public leadership in times of crisis (e.g., Boin and 't Hart, 2003; Boin et al., 2016, Hadley et al., 2011; Comfort and Okada, 2013; Hale et al., 2006; Van Wart and Kapucu, 2011) but these tend to be somewhat empirically disconnected from the substantial number of studies on crisis-induced organizational learning (e.g., Birkland, 2006; Deverell, 2009; Carley and Harrald, 1997; Choularton, 2001; Toft and Reynolds, 1994). The extent that learning occurs differs from crisis to crisis and the literature has yet to clarify the factors that explain the extent of crisis-induced learning (Stern, 1997; Deverell, 2009, 2010). A recent study suggests a coherent pattern in public leaders' orientations in their crisis-response activities (De Vries, 2016), of which crisis-induced learning is a central one. Systematic empirical evidence on crisis leadership and crisis-induced learning needs to be established to address this knowledge gap (Smith and Elliot, 2007), including larger- $n$ studies and more systematic operationalizations of crisis-induced learning (Dekker and Hansén 2004, p. 141). This is a challenge because learning from a crisis is, by definition, different from the well-studied process of learning in normal

\footnotetext{
* Corresponding author.

E-mail address: w.g.broekema@fgga.leidenuniv.nl (W. Broekema).
} 
situations (Moynihan, 2008).

The present study aims to contribute to this field by providing a more refined operationalization of public leaders' crisis-induced organizational learning orientations. These learning orientations comprise cognitive learning, behavioral learning, accountability, and external communication dimensions. We further argue that these leaders' public service motivation (PSM) - their motivation to pursue the public good (see Perry, 1996) - explains the variation in these orientations. Accordingly, we pose the research question: To what extent do public leaders' public service motivation affect their organizational learning orientation in the wake of a crisis? We hypothesize that public leaders with relatively high levels of PSM will be more strongly oriented towards instrumental learning. Conversely, public leaders with relatively low levels of PSM are expected to have a stronger orientation towards political learning.

To explore the organizational learning orientations of public leaders and test our hypotheses, we sent a survey to all 391 mayors of the Dutch municipalities with questions about a hypothetical crisis in their municipality since mayors have a key leadership function in the Dutch crisis management system. We asked the respondents to indicate the importance they would attach to several aspects of learning. We received 209 valid responses (response rate $=53$ percent). The items included in the survey on specific aspects of crisis-induced learning were derived from previous surveys in the field of organizational learning (Garvin et al., 2008; Goh and Richards, 1997; Chiva et al., 2007; Marsick and Watkins, 2003) and from the crisis management literature. We also included the public service motivation measurement scale of Kim et al. (2013) plus a range of control variables tapping the characteristics of the mayor and the municipality.

Below, we first discuss the literature on crisis-induced organizational learning, as a key challenge for public leaders, and how this might be associated with public leaders' PSM. After a brief description of the context of mayors in the Dutch system of crisis management, we discuss our empirical design. After presenting the results of our descriptive and explanatory analyses, we conclude with a discussion on the relevance of our findings.

\section{Theoretical framework}

\subsection{Leadership challenges in the wake of a crisis}

Public leaders play a central role in the governance of crises, situations in which they are confronted with enormous challenges (Boin and 't Hart, 2003; Boin et al., 2016; Comfort and Okada, 2013). Entrusted with extended responsibilities and competences - often far beyond the scope of their normal duties - public leaders are expected to guide their organizations through difficult times. In a crisis situation, public leaders represent government to the public and have to provide sense and meaning to events (Boin et al., 2016). Directing the crisis management organization, public leaders have to take decisions with potentially far-reaching consequences under very complex circumstances (Boin et al., 2016; Comfort and Okada, 2013). They have to do this in a situation of chaos and stress, under time pressures, and often with only incomplete or unreliable information and few opportunities to consult other parties (De Vries, 2016). In a crisis situation, the environment is often heavily politicized since political actors, the media, and a variety of stakeholders can create immense political pressure (Brändström and Kuipers, 2003).

\subsection{The challenge of organizational learning in times of crisis}

In the immediate aftermath of a crisis, one of the key challenges facing a public leader is to initiate a process of organizational learning (Boin et al., 2008; Schiffino et al., 2016; Deverell, 2010). Learning is of central importance because of the devastating and long-lasting physical, economic, ecological, and social consequences that crises can have. Through crisis-induced learning, a public organization can improve its crisis-response activities and incorporate measures to prevent future crises. Crisis-induced learning differs from organizational learning in regular times in many ways (Moynihan, 2008). The public, the media, parliament, and other stakeholders typically demand of government to learn lessons from a crisis and can put strong pressures on public leaders to initiate learning (Broekema, 2016). In theory, a crisis can function as a catalyst for learning. A crisis can shake up a system, putting an end to long periods of institutional lock-in, and suddenly enable major organizational change. In the literature such situations are known as critical junctures, or windows of opportunity (Capoccia and Kelemen, 2007; Kingdon, 2003). Crises may reveal structural defects in a system that would otherwise have remained undetected, produce an upsurge in new information (Birkland, 2006), and establish the political consensus among stakeholders that is necessary to achieve change.

Despite the merits of crisis-induced learning, a vast body of research reveals that, in reality, public organizations face major difficulties in learning from a crisis (see Smith and Elliot, 2007). Note that organizational change after a crisis should not be equated with learning, because change does not necessarily imply an improved performance (Fiol and Lyles, 1985; May, 1992). The context of a crisis also creates barriers and introduces complexities to learning (Roux-Dufort, 2000; Stern, 1997). Uncertainty, time pressures, a lack of reliable information, and disagreements on the causes and consequences of crisis events make it difficult to reflect adequately on events (Broekema, 2016). Moreover, in a crisis, organizations generally adopt a defensive attitude, making it difficult to identify errors and discuss improvements. Consequently, a 'crisis learning paradox' emerges: the very crisis situation that makes learning imperative also impedes the accomplishment of learning (Dekker and Hansén, 2004, p. 211).

\subsection{Crisis-induced learning partitions}

On the basis of the organizational learning and crisis management literature, we can theoretically distinguish between two dimensions of crisis-induced learning: (1) instrumental learning; i.e. a 'technical' process of adopting organizational adjustments based on the new knowledge and understanding acquired, and (2) political learning; a process of finessing the organization's political strategies and activities (drawing on May, 1992). We included the political learning dimension, because of the particular importance of political processes in the context of a crisis.

\subsubsection{Instrumental learning}

Instrumental learning is typically geared towards structural improvements in an organization. These embrace: (a) a cognitive process the acquisition of new knowledge (cognitive dimension) and (b) a behavioral process - the transfer of this new knowledge into organizational adjustments (behavioral dimension) (Fiol and Lyles, 1985; Broekema et al., 2017).

Cognitive dimension (knowledge acquisition). Acquiring new knowledge and understanding is a fundamental part of organizational learning (Argyris and Schön, 1978). New information can provide an organization with insights into the underlying factors that caused the crisis and weaknesses in its crisis response activities (Birkland, 2006). New knowledge can be obtained through reflecting on past events, among others by means of a public inquiry, evaluation studies, investigative journalism, and discussions in networks (Dekker and Hansén, 2004). Post-crisis evaluations are a common and accepted way of detecting organizational problems, despite some scholars questioning the actual contribution of evaluation reports to learning (Turner, 1976; Elliott, 2009). Organizational learning is not only about bringing new knowledge to the organization; it also concerns its proper dissemination within the organization (Huber, 1991). Processes of interpretation and sense-making are essential in making the knowledge appropriate for a 
transfer into organizational actions, and this is challenging from a crisis-learning perspective (Weick, 1995; Boin et al., 2016).

Behavioral dimension (organizational adjustments). After an organization has acquired new knowledge, actions can be initiated through holding debates about new ideas in groups and teams within the organization. Subsequently, these ideas have to be translated into adjustments in the way the organization behaves (Fiol and Lyles, 1985; Downe et al., 2004). This action part of learning can be considered as an implementation process that also has its related challenges (Pressman and Wildavsky, 1984; Torenvlied, 2000). One way to accomplish changes in peoples' behaviors within an organization is through the top-down adoption of formal changes, such as creating or revising handbooks, protocols, procedures, or legislation (Birkland, 2006). However, top-down formal adjustments may not necessarily result in the desired behavioral changes (Birkland, 2006; Fiol and Lyles, 1985). Alternatively, changing the organizational culture can be a more profound way of learning, and this involves changing "beliefs and precautionary norms [...] to fit the newly gained understanding of the world" (Turner, 1976, p. 381). However, this is recognized as a rather difficult process and "full cultural readjustment [after a crisis] represents an ideal that is rarely achieved" (Smith and Elliot, 2007, p. 520). As a further complication, organizational adjustment often takes place within a network of organizations (Moynihan, 2008).

\subsubsection{Political learning}

Political learning is the process of improving an organization's political activities, and is typically geared towards the more short-term descaling and settlement of a crisis. Crises tend to politicize rapidly, with a range of actors competing intensively over various interests (Boin et al., 2008; Broekema, 2016), which can evolve quickly and unexpectedly (Brändström and Kuipers, 2003). In the immediate aftermath of a crisis, it is crucial that organizations deal adequately with its political aspects. This means they have to constantly adapt their political activities to the emerging context. Political learning requires "[...] a finely honed sense of the formal and informal rules of the political game and [to] know when such rules may best be invoked, stretched or ignored to best advantage" (Stern, 1997, p. 71). In times of high public scrutiny, organizations need to start dealing with processes of blame allocation, framing interpretations, and refining their political strategies in order to minimize reputational damage (Boin et al., 2009; Coombs, 2006). In the context of a crisis, a core part of the political process involves adequately organizing crisis communications to take account of stakeholder interests, map public support, and establish a dominant interpretation of the situation (Coombs, 2012).

\subsection{Public service motivation and crisis-induced learning}

The complex circumstances often turn crisis decision-making into a hurried situational judgement based on a leader's intuitions, established before the crisis, rather than a profound analytical assessment of alternative courses of action (Gilpin and Murphy, 2008). Strong political pressure, time constraints, chaos, stress, and insufficient information during a crisis result in a public leader's personal characteristics playing a more important role in decision making than in more regular situations. That is, personal characteristics are an important factor in crisis decision making (Jong et al., 2016; Van Wart and Kapucu, 2011; De Vries, 2016; Deverell, 2010). Jong et al., in their study on mayoral leadership in times of crisis, concluded that 'decision making is positively related to the level of intrinsic motivation to lead and the ability to motivate others in a crisis' (2016, p. 54). It has also been suggested that the large variation in the decisions that public leaders take in response to crises is related to personal characteristics of their leadership (De Vries, 2016).

In the present study, we argue that a public leader's public service motivation (PSM) helps to explain the priorities they assign to organizational learning activities in the wake of a crisis. PSM has been studied extensively in the field of public administration in the past two decades
(Perry and Hondeghem, 2008) and can be defined as "the motivational force that induces individuals to perform meaningful public service (i.e., public, community, and social service)" (Brewer and Selden, 1998, p. 417). It is about holding "motives and action in the public domain that are intended to do good for others and shape the well-being of society" (Perry and Hondeghem, 2008, p. 3). The literature indicates a positive relationship between PSM and behavior that is seen by the individual as benefiting society (e.g., Andersen and Serritzlew, 2012). Nevertheless, individuals might be confronted with having to make a trade-off between the interests of the general public and those of themselves and individual clients. Jensen and Andersen (2015), for example, found that medical practitioners with a higher PSM, by prescribing fewer antibiotics (which is better for society due to problems of increasing resistance), focus more on serving the collective good. However, by doing so, they are being less responsive to the individual patient. Brewer and Selden (1998), when studying the link between PSM and whistleblowing, found that individuals with a higher PSM, motivated by their concern for the public interest, report wrongdoings more frequently, even if this may run counter to their self-interests (putting their job security at risk) or the interests of colleagues in the organization. In a contrasting finding, Schott et al. (2018) found that, when confronting public servants with dilemma scenarios in which their core work values were in conflict with each other, PSM had no effect on the respondents' decision-making.

Learning in the wake of a crisis also entails trade-offs for public leaders as, in a short time frame, they have to decide which learning activities to prioritize. Under complex circumstances, these public leaders have to organize a range of simultaneous activities, such as acquiring an understanding of the causes of the crisis, collaborating with a variety of stakeholders, adapting organizational procedures, publishing media reports, and organizing press meetings. Here, the combination of an overloaded agenda and serious time pressures compels public leaders to prioritize certain learning activities. There is a potential tradeoff between putting effort into instrumental learning, i.e., acquiring an understanding of the crisis and implementing appropriate adaptations in the organization, and engaging in political learning, such as by adapting the organization's political strategies. Following a similar logic to Jensen and Andersen (2015) and Brewer and Selden (1998), and taking into account that a crisis situation poses a sudden threat to the vital interests of society (Rosenthal et al., 2001), we expect that public leaders with a strong motivation to serve the public good to be most concerned with making structural improvements in the organization that increase the organization's ability to prepare for and prevent future crises. Thus, their actions are likely to be aimed at accomplishing both cognitive and behavioral forms of instrumental learning. However, public leaders also have to manage blame and control reputational damage to the organization, while they may also fear losing their own position (Coombs and Holladay, 2002). Taking into account the complexities of learning from a crisis (Stern, 1997), we expect public leaders with a relatively weak motivation to serve the public good to be more concerned with the short-term political implications of a crisis, and consequently to be more oriented towards political learning processes. On the basis of these arguments, we therefore hypothesize that:

H1a. Public leaders' level of public service motivation is positively associated with their orientation towards the organization's cognitive instrumental learning in the immediate aftermath of a crisis.

H1b. Public leaders' level of public service motivation is positively associated with their orientation towards the organization's behavioral instrumental learning in the immediate aftermath of a crisis.

H2. Public leaders' level of public service motivation is negatively associated with their orientation towards the organization's political learning in the immediate aftermath of a crisis. 
Before discussing the methods we used to measure crisis-induced learning and PSM, in the next section we will first explain the important role of Dutch mayors in crisis management.

\section{Dutch mayors as commanders-in-chief in times of crisis}

Dutch mayors are our object of study. In the Netherlands, mayors hold specific competences and responsibilities in the field of public security within the territory of their municipality. Beyond a general responsibility for public security, mayors hold the leading responsibility for crisis and disaster management (Municipal Act, 1992). In times of crisis, the mayor is the commander-in-chief of the municipal crisis management team and charged with the coordination of the local crisis response activities. The mayor is responsible for an adequate coordination of the crisis response as well as strategic administrative decision-making (De Vries, 2016; NGB, 2013). The mayor has direct authority over the deployment of the fire services and medical services operations, and can issue an emergency decree (Municipal Act, 1992). Further, mayors are central players in the local crisis management network of the wider safety regions (Min. VenJ, 2013). In effect, mayors represent the municipality within a multidisciplinary network of actors, including regular emergency services, i.e., police, fire, and ambulance services, as well as public and private actors within the context of the crisis (Scholtens, 2008). During a crisis, the mayor is responsible for external crisis communication, for example by organizing press conferences (NGB, 2013; Min. VenJ, 2013). Thus, overall, in the Netherlands, mayors have key leadership responsibilities and tasks in the area of public security within their municipality, and these are particularly extensive in times of crisis, when the mayor in effect becomes the commander-in-chief.

\section{Methodology}

\subsection{Data collection}

\subsubsection{Survey of Dutch mayors}

In the present study, we collected data about the relationship between public leaders' PSM and their organizational learning priorities in the wake of a crisis, using a questionnaire sent out to all 391 Dutch mayors ${ }^{1}$ in fall 2015. In order to ensure the survey's validity, we conducted a pre-test and further discussed the questionnaire with two municipal officials and two senior scholars. This led to some minor adjustments regarding formulations. The part of the broader survey that was relevant for this study consisted of three sections. First, there were a number of general questions to assess the background of the respondent. Second, the respondents were asked to express their level of agreement with a number of PSM-related items. Third, we confronted the respondents with a hypothetical crisis situation, described in 'general' terms. They were then asked to indicate the priority they would give to several aspects of learning in the wake of this hypothetical crisis.

In our initial approach, the mayors were contacted through the official e-mail addresses of the municipalities and asked to participate in an online survey. An identical hard-copy version of the survey was sent out by post one month later. Another month later, a friendly final reminder was sent by e-mail. In total, combining the responses collected with the online data collection software (Qualtrics) and the hard-copies returned, we had data from 209 mayors (a response rate of 53 percent).

Particularly since mayoral activities in the wake of a crisis are politically sensitive, our study could be influenced by social desirability

\footnotetext{
${ }^{1}$ The Netherlands, excluding the Dutch Caribbean, was made up of 393 municipalities in 2015. Two mayoral positions (Neerijnen and Bloemendaal) were vacant at the time of the survey, with the official duties performed by a mayor of a neighboring municipality. Thus, our maximum sample at the time of the survey was 391 mayors.
}

(Nederhof, 1985). We tried to minimize this risk by referring to a nonspecific hypothetical crisis situation and by also guaranteeing anonymity. There are several indicators that suggest our sample is representative of the total population of municipalities and mayors in the Netherlands. Here, we compared the distribution of the sample's municipality populations with official data published by Statistics Netherlands (CBS, 2017), as well as the respondents' political affiliations ${ }^{2}$ and the political composition of the executive boards to data published by the Ministry of the Interior (Min. BZK, 2014). All three statistics suggest our sample is a good match to the wider population. The mayors participating in the survey had a wide range of ages (36-74) and the number of their crisis experiences also varied widely (0-8). No significant differences were found between the data in the online and hard-copy formats.

\subsubsection{Measurement of crisis-induced learning priorities}

The literature lacks an established scale for measuring crisis-induced learning. Therefore, in order to measure learning orientation in a crisis, we developed 21 items that each tap into an aspect of crisisinduced learning. These items were based on existing scales for organizational learning: the Learning Organization Survey (Garvin et al., 2008), the Organizational Learning Survey (Goh and Richards, 1997), the Organizational Learning Capability scale (Chiva et al., 2007), and the Dimensions of the Learning Organizations Questionnaire (DLOQ) (Marsick and Watkins, 2003). In addition, we drew on insights from the crisis management literature on crisis-induced learning related processes (see Table 1).

Most of the items in the existing organizational learning surveys were not directly transferable to a crisis context, largely because they are related to continuous long-term learning processes in an organization. An example being "My organization measures the results of the time and resources spent on training" included in the DLOQ (Marsick and Watkins, 2003, p. 144). We therefore adopted the items we saw as relevant by adjusting them to a crisis context. Some items needed minor adjustments to match Dutch crisis management practice, which we carried out based on the Dutch crisis management handbook for mayors (NGB, 2013). The resulting 21 items on crisis-induced learning relate to the dimensions of instrumental learning or of political learning, with the former being further subdivided into knowledge acquisition and organizational adjustments (see Table 1). The questionnaire used a ten-point Likert scale to assess the importance each mayor gave to each aspect of crisis-induced learning (ranging from 1 - lowest priority, to 10 - highest priority).

\subsubsection{Measurement of public service motivation}

For measuring PSM, we used the 16-item measurement instrument developed by Kim et al. (2013). This well-established measurement instrument has been validated across 12 countries and builds upon the work of Perry (1996) and Kim and Vandenabeele (2010). The instrument distinguishes four dimensions of PSM: compassion (COM), selfsacrifice (SS), attraction to public service (APS), and commitment to public values (CPV).

\subsubsection{Measurement of control variables}

In the survey, we measured several individual characteristics of the mayors, i.e., their gender $[$ female $=0$, male $=1]$; age $[2015$ - year of birth]; experience as mayor [years in function]; political affiliation [none, Christian democrats ('CDA'), liberal party ('VVD'), social democrats ('PvdA'), as the three main parties to which mayors are affiliated, and 'other']; number of crises experienced while in office [number]. We also included a characteristic to reflect the size of the municipality, i.e.,

\footnotetext{
${ }^{2}$ Although, mayors in the Netherlands are not democratically elected but appointed, they are often affiliated to a political party. The appointment of a mayor is based on a recommendation from the municipal council.
} 
Table 1

Item generation for crisis-induced learning.

\begin{tabular}{|c|c|c|c|}
\hline Dimension and processes/aspects & \multicolumn{2}{|l|}{ Item } & Literature source \\
\hline \multicolumn{4}{|l|}{ Instrumental learning } \\
\hline \multicolumn{4}{|c|}{ Cognitive dimension (knowledge acquisition) } \\
\hline Information acquisition & IC1. & The systematic collection of information & $\begin{array}{l}\text { Marsick and Watkins (2003); Garvin et al. (2008); Argyris and Schön } \\
\text { (1978); Turner (1976); Elliott (2009); }\end{array}$ \\
\hline Time for reflection & IC2. & Despite the workload, create space and time for reflection & $\begin{array}{l}\text { Marsick and Watkins (2003); Garvin et al. (2008); Toft and Reynolds } \\
\text { (1994) }\end{array}$ \\
\hline Sense- and meaning making & IC3. & Provide meaning to the events & Boin et al. (2016); Weick (1995); Boin and 't Hart (2003); Huber (1991) \\
\hline Knowledge dissemination & IC4. & $\begin{array}{l}\text { Internal dissemination of new information through the } \\
\text { organization }\end{array}$ & $\begin{array}{l}\text { Marsick and Watkins (2003); Goh and Richards (1997); Garvin et al. } \\
\text { (2008); Huber (1991) }\end{array}$ \\
\hline Evaluation study & IC5. & $\begin{array}{l}\text { Have an evaluation study conducted by an external } \\
\text { organization }\end{array}$ & Turner (1976); Elliott (2009) \\
\hline Learning environment & IC6. & $\begin{array}{l}\text { Create an atmosphere in which employees can readily say } \\
\text { what they think }\end{array}$ & $\begin{array}{l}\text { Marsick and Watkins (2003); Garvin et al. (2008); Chiva et al. (2007); } \\
\text { Carley and Harrald (1997); Turner (1976) }\end{array}$ \\
\hline Openness to new ideas & IC7. & Create openness to new ideas of employees & Garvin et al. (2008); Goh and Richards (1997); Chiva et al. (2007) \\
\hline \multicolumn{4}{|c|}{ Behavioral dimension (organizational re-adjustments) } \\
\hline Adaptation & IB1. & The quick implementation of improvements & May (1992); Birkland (2006); Carley and Harrald (1997) \\
\hline Procedural changes & IB2. & Reconsider organizational procedures and protocols & Birkland (2006), Carley and Harrald (1997); Toft and Reynolds (1994) \\
\hline Cultural re-adjustments & IB3. & $\begin{array}{l}\text { Determine whether a change in the organizational culture } \\
\text { is needed }\end{array}$ & Garvin et al. (2008); Turner (1976); Senge (1990) \\
\hline Learning culture & IB4. & Launch training and courses for employees & Garvin et al. (2008); Weick and Sutcliffe (2001); Senge (1990) \\
\hline Network learning & IB5. & $\begin{array}{l}\text { Improve affairs in conjunction with the network outside } \\
\text { the organization }\end{array}$ & $\begin{array}{l}\text { Chiva et al. (2007); Moynihan (2008); Kapucu (2006); Downe et al. } \\
\text { (2004) }\end{array}$ \\
\hline Debating in groups & IB6. & Debate new ideas in group/teams & $\begin{array}{l}\text { Marsick and Watkins (2003); Goh and Richards (1997); Garvin et al. } \\
\text { (2008); Chiva et al. (2007) }\end{array}$ \\
\hline \multicolumn{4}{|c|}{ Political learning (refinement of political activities) } \\
\hline Political responsibility & P1. & $\begin{array}{l}\text { Examine whether parties have acted according to their } \\
\text { authorities and responsibilities }\end{array}$ & Boin et al. (2008,2016); Toft and Reynolds (1994); Olson (2000) \\
\hline Political strategy & P2. & Refine the political strategy & May (1992); Birkland (2006); Coombs (2006); Boin and 't Hart (2003) \\
\hline External communication & P3. & $\begin{array}{l}\text { Frequently communicate to the external media about } \\
\text { developments }\end{array}$ & Coombs (2012); Seeger et al. (2003) \\
\hline Allocation of blame & P4. & Pay attention to the allocation of blame & Boin et al. (2008); Broekema (2016); Olson (2000); Coombs (2006) \\
\hline Monitoring of public opinion & P5. & Monitor public opinion, for example through social media & Chiva et al. (2007); Seeger et al. (2003); Toft and Reynolds (1994) \\
\hline Attention to interests of stakeholders & P6. & Take into account the interests of external parties involved & Brändström and Kuipers (2003); Boin et al. (2008); Kapucu (2006) \\
\hline Mapping public support & P7. & Map public support for decisions & Chiva et al. (2007); Coombs (2012) \\
\hline Reputational damage & P8. & Limit reputational damage to the organization & Christensen et al. (2016); Coombs and Holladay (2002); Coombs (2006) \\
\hline
\end{tabular}

the number of inhabitants $[<15,000=0, \quad 15,000-25,000=1$, $25,000-50,000=2,50,000-100,000=3,>100,000=4]$. These are official categories adopted from Statistics Netherlands (CBS, 2017).

\section{Results and analysis}

In the analysis, we first present descriptive statistics for the crisisinduced learning items and explore the related dimensions. Subsequently, we discuss the composition of the PSM construct. Finally, we present the results of the analysis as to the effects of the various PSM dimensions on the range of crisis-induced learning dimensions.

\subsection{Mayors' learning priorities in the wake of a crisis: four crisis-induced learning dimensions}

The descriptive statistics of the crisis-induced learning items (see Table 2) show that mayors attach significant importance to all the organizational learning processes in the immediate aftermath of a crisis (means $=5.33-8.82$ on a $0-10$ scale with $\mathrm{N}=185-194$ ). The average mean score of all items is 6.92 . Further, there are substantial variations in the scores for all the items (s.d. $=1.20-2.15$ ). The largest variations found were for the 'authority and responsibility' (P1) (s.d. $=2.15$ ), 'change in organizational culture' (IB3) (s.d. $=2.12$ ), and 'reconsidering organizational procedures' (IB2) $($ s.d. $=2.08)$ items. The most consistent scoring was for the "meaning to the events" (IC3) (s.d. $=1.20$ ) and 'systematic collection of information' (IC1) (s.d. $=1.31)$ items.
Table 2

Descriptive statistics of the 21 crisis-induced learning items before regrouping.

\begin{tabular}{llllll}
\hline Dimensions and items & N & Mean & S.d. & Min. & Max. \\
\hline Instrumental learning & & & & & \\
$\quad$ Cognitive dimension & & & & & \\
IC1. Systematic collection of information & 185 & 7.50 & 1.31 & 3 & 10 \\
IC2. Rest and time for reflection & 187 & 7.72 & 1.45 & 1 & 10 \\
IC3. Meaning to the events & 185 & 8.45 & 1.20 & 5 & 10 \\
IC4. Dissemination of information & 185 & 6.77 & 1.61 & 2 & 10 \\
IC5. Evaluation by external organization & 190 & 6.62 & 2.03 & 1 & 10 \\
IC6. Open atmosphere & 190 & 8.03 & 1.43 & 2 & 10 \\
IC7. Openness to new ideas & 185 & 7.47 & 1.69 & 2 & 10 \\
Behavioral dimension & & & & & \\
IB1. Quick implementation of improvements & 193 & 7.08 & 1.83 & 1 & 10 \\
IB2. Reconsider organizational procedures & 191 & 5.85 & 2.08 & 1 & 10 \\
IB3. Change in organizational culture & 190 & 5.81 & 2.12 & 1 & 10 \\
IB4. Trainings and courses & 190 & 6.06 & 1.94 & 1 & 10 \\
IB5. Networking outside the organization & 185 & 7.24 & 1.56 & 2 & 10 \\
IB6. Debate new ideas in teams & 191 & 6.26 & 2.01 & 1 & 10 \\
Political learning & & & & & \\
P1. Authority and responsibility & 194 & 6.27 & 2.15 & 2 & 10 \\
P2. Political strategy & 187 & 6.45 & 1.83 & 2 & 10 \\
P3. External communication to the media & 188 & 7.45 & 1.67 & 2 & 10 \\
P4. Allocation of blame & 187 & 5.33 & 2.00 & 1 & 10 \\
P5. Monitoring public opinion & 186 & 7.58 & 1.39 & 2 & 10 \\
P6. Interests of external parties & 186 & 7.04 & 1.40 & 3 & 10 \\
P7. Public support for decisions & 185 & 6.99 & 1.57 & 2 & 10 \\
P8. Limiting reputational damage & 187 & 6.45 & 1.83 & 2 & 10 \\
\hline
\end{tabular}


Table 3

Results of principal component analysis for the 19 crisis-induced learning items.

\begin{tabular}{|c|c|c|c|c|}
\hline Dimensions and items & $\begin{array}{l}\text { Factor } 1 \\
\text { Eigenvalue }=6.58\end{array}$ & $\begin{array}{l}\text { Factor } 2 \\
\text { Eigenvalue }=2.30\end{array}$ & $\begin{array}{l}\text { Factor } 3 \\
\text { Eigenvalue }=1.79\end{array}$ & $\begin{array}{l}\text { Factor } 4 \\
\text { Eigenvalue }=1.15\end{array}$ \\
\hline \multicolumn{5}{|l|}{ Instrumental learning } \\
\hline \multicolumn{5}{|l|}{ Cognitive learning } \\
\hline IC1. Systematic collection of information & 0.03 & 0.19 & 0.33 & 0.68 \\
\hline IC2. Rest and time for reflection & 0.25 & 0.05 & 0.06 & 0.80 \\
\hline IC3. Meaning to the events & 0.08 & -0.04 & 0.47 & 0.56 \\
\hline IC6. Open atmosphere & 0.45 & 0.11 & 0.14 & 0.52 \\
\hline \multicolumn{5}{|l|}{ Behavioral learning } \\
\hline IB3. Change in organizational culture & 0.69 & 0.51 & 0.04 & -0.09 \\
\hline IB4. Trainings and courses & 0.76 & 0.38 & 0.05 & 0.05 \\
\hline IB5. Networking outside the organization & 0.74 & 0.05 & 0.15 & 0.22 \\
\hline IB6. Debating new ideas in organization & 0.76 & 0.13 & 0.03 & 0.15 \\
\hline IC7. Openness to new ideas & 0.77 & -0.02 & 0.03 & 0.38 \\
\hline \multicolumn{5}{|l|}{ Political learning } \\
\hline \multicolumn{5}{|l|}{ Accountability } \\
\hline P1. Authority and responsibility & 0.14 & 0.83 & 0.20 & 0.12 \\
\hline P4. Allocation of blame & 0.11 & 0.64 & 0.27 & -0.01 \\
\hline IC5. Evaluation by external organization & 0.02 & 0.62 & 0.09 & 0.39 \\
\hline IB1. Quick implementing improvements & 0.42 & 0.53 & 0.12 & 0.16 \\
\hline IB2. Reconsidering organizational procedures & 0.57 & 0.62 & 0.04 & -0.14 \\
\hline \multicolumn{5}{|l|}{ External communication } \\
\hline P3. External communication to the media & 0.03 & 0.27 & 0.73 & 0.07 \\
\hline P5. Monitoring public opinion & -0.09 & 0.20 & 0.78 & 0.16 \\
\hline P6. Interests of external parties & 0.19 & 0.09 & 0.69 & 0.20 \\
\hline P7. Public support for decisions & 0.55 & 0.00 & 0.58 & 0.01 \\
\hline IC4. Dissemination of information & 0.44 & 0.05 & 0.51 & 0.27 \\
\hline
\end{tabular}

Factor loadings after Varimax rotation.

Bold: highest factor loading for each item $(\geq 0.5)$.

An explorative principal component factor analysis with Varimax rotation (using Stata) of the 21 crisis-induced learning items was carried out, and this identified four underlying dimensions which we labelled as cognitive learning, behavioral learning, political accountability, and external communication (see Table 3 ). ${ }^{3}$ The items were categorized on the basis of their highest factor loading; all of which were above 0.5 .

The items within the 'cognitive learning' dimension (IC1, IC2, IC3, and IC6) address processes of knowledge acquisition and reflection on crisis events, and therefore correspond well with the theoretically derived concept. This is the weakest of the four dimensions (Eigenvalue $=1.15$ ). The items grouped within the behavioral learning dimension (IB3, IB4, IB5, IB6, IC7) are also largely in line with our expectations in that they all relate to adjusting the organizational culture and disseminating knowledge within the organization. This was by far the strongest factor, with an Eigenvalue of 6.58.

However, the political learning structure that emerged is quite different from what we had expected on the basis of theory. We found two distinct political dimensions: one related to dealing with accountability processes and one related to refining external communication. The 'accountability' dimension included the 'authority and responsibility' and 'allocation of blame' items (P1 and P4). In addition to these two items, the dimension included one item related to external evaluation (IC5) and two linked to quick and procedural changes (IB1 and IB2). The inclusion of an item on external evaluation appears reasonable since external evaluations are often considered as playing a central role in the post-crisis accountability process (Boin et al., 2016;

\footnotetext{
${ }^{3}$ We excluded item P8. 'Limiting reputational damage', because of its very low factor loadings $(<0.36)$ on all four factors. We also excluded item P2. 'Political strategy', despite its acceptable loading on the behavioral learning dimension because, in the context of an explorative study, it made offering a clear interpretation of the resulting factor difficult.
}

Resodihardjo, 2006). The relatively high loadings of the quick and procedural change items onto this accountability dimension is more of a surprise. The analysis suggests that engaging in political activities and 'reconsidering procedures' and 'quick implementation' themes tap into related prioritizing patterns. Reflecting on the crisis management literature on these two themes of crisis-induced learning, our result suggest that public leaders do not particularly view quick and procedural change as a structural way of learning, in contrast to other organizational forms of adjustments such as changing culture or training programs. The results suggest that public leaders implement quick and procedural changes as a political solution to external pressures (May, 1992; Broekema, 2016).

The factor analysis shows that the remaining political items (P3, P5, P6, and P7) load onto the second political learning dimension that captures processes related to refining external communication. One further item, the 'dissemination of information' (IC4), also loads onto this dimension but this can easily be understood as a communication process.

\subsection{Two dimensions of public service motivation}

The mayors, on average, gave the PSM items consistently high scores (mean $=6.83-8.51, \mathrm{~N}=205-208$ ). The overall mean score of all the items was 7.62. However, there were substantial variations among the mayors on all the items (s.d. $=0.85-1.60$ ). The highest variations were for the "It is important for me to contribute to the common good" (CPI2) (s.d. = 1.60) and "I believe in putting civic duty before self" (SS3) (s.d. = 1.39) items. The smallest variations were recorded for the "to act ethically is essential for public servants" (CPV7) (s.d. $=0.85$ ) and "I admire people who initiate or are involved in activities to aid my community" (APS5) (s.d. $=0.95$ ) items. The observation that mayors give the PSM construct high scores is not surprising given their large public responsibilities. Mayors in the Netherlands also serve as representatives of the public interest and the 
Table 4

Results of principal component analysis for the 16-item PSM measure.

\begin{tabular}{|c|c|c|c|c|}
\hline & \multicolumn{2}{|c|}{ Dimensions and items } & Factor 1 Eigenvalue $=7.72$ & Factor 2 Eigenvalue $=1.52$ \\
\hline \multicolumn{5}{|c|}{ Compassion and Self-Sacrifice (COM/SS) } \\
\hline \multirow[t]{4}{*}{ Compassion (COM) } & COM2. & I feel sympathetic to the plight of the underprivileged & 0.76 & 0.33 \\
\hline & COM3. & I empathize with other people who face difficulties & 0.65 & 0.43 \\
\hline & COM5. & I get very upset when I see other people being treated unfairly & 0.38 & 0.42 \\
\hline & CoM6. & Considering the welfare of others is very important & 0.61 & 0.53 \\
\hline \multirow{4}{*}{ Self-sacrifice (SS) } & SS1. & I am prepared to make sacrifices for the good of society & 0.72 & 0.24 \\
\hline & SS3. & I believe in putting civic duty before self & 0.67 & 0.37 \\
\hline & SS4. & I am willing to risk personal loss to help society & 0.75 & 0.19 \\
\hline & SS7. & $\begin{array}{l}\text { I would agree to a good plan to make a better life for the poor, even if it } \\
\text { costs me money }\end{array}$ & 0.81 & -0.05 \\
\hline \multicolumn{5}{|c|}{ Attraction to Public Service and Values (APS/CPV) } \\
\hline \multirow[t]{4}{*}{$\begin{array}{l}\text { Attraction to Public Service } \\
\text { (APS) }\end{array}$} & APS5. & $\begin{array}{l}\text { I admire people who initiate or are involved in activities to aid my } \\
\text { community }\end{array}$ & 0.38 & 0.69 \\
\hline & APS7. & It is important to contribute to activities that tackle social problems & 0.66 & 0.49 \\
\hline & CPI1. & Meaningful public service is very important to me & 0.16 & 0.74 \\
\hline & CPI2. & It is important for me to contribute to the common good & 0.33 & 0.67 \\
\hline \multirow{4}{*}{$\begin{array}{l}\text { Commitment to Public Values } \\
\text { (CPV) }\end{array}$} & CPV1. & I think equal opportunities for citizens are very important & 0.42 & 0.52 \\
\hline & CPV2. & $\begin{array}{l}\text { It is important that citizens can rely on the continuous provision of public } \\
\text { services }\end{array}$ & 0.10 & 0.84 \\
\hline & CPV6. & $\begin{array}{l}\text { It is fundamental that the interests of future generations are taken into } \\
\text { account when developing public policies }\end{array}$ & 0.27 & 0.63 \\
\hline & CPV7. & To act ethically is essential for public servants & 0.26 & 0.66 \\
\hline
\end{tabular}

Factor loadings after Varimax rotation.

Bold: highest factor loading for each item ( $\geq 0.5$ ).

face of the community to the outside world (as 'head of the community'). Although PSM measurement scales have been frequently tested, they have been mostly applied to civil servants and, occasionally, to private-sector employees (e.g., Taylor, 2010; Liu et al., 2012; Andersen and Kjeldsen, 2013), and especially to those providing public services (e.g., Andersen and Serritzlew, 2012; Jensen and Andersen, 2015). This study shows that this scale can be applied to public office holders as well.

We conducted a principal component factor analysis with Varimax rotation of the 16 PSM items to test whether the same dimensions identified by Kim et al. (2013, p. 92) are present in our dataset on mayors. From our data, we were able to identify two distinct factors in the PSM construct (see Table 4), each combining two of the four dimensions reported by Kim et al. (2013). All but one of the items that are in Kim et al.'s COM (compassion) and SS (self-sacrifice) dimensions load highly onto our first factor which we label 'compassion and self-sacrifice' (COM/SS). Also loading highly onto this factor is one item from Kim et al.'s 'attraction to the public service' dimension: finding it important to contribute to activities that tackle social problems (APS7). Our second factor includes all the other items from Kim et al.'s APS (attraction to the public service) and CPV (commitment to public values) dimensions, which we therefore labeled 'attachment to public service and values' (APS/CPV).

\subsection{The effect of public service motivation on crisis-induced learning}

To study the effect of PSM on the crisis-learning orientation dimensions, we conducted a series of OLS regression analyses using Stata. The two PSM dimensions were treated as independent variables and the four crisis-induced learning dimensions as distinct dependent variables. The mayor's 'gender', 'age', 'mayor tenure', 'political affiliation', and 'crisis experience', and the 'municipality population size' were included as control variables. The results are presented in Table 5 and show a significant positive effect of PSM on the prioritization of both instrumental learning and political learning processes in the wake of a crisis. The R-squared values range from 0.09 to 0.19 .

First, addressing cognitive learning, we find that the 'compassion and self-sacrifice' (COM/SS) component of PSM has a small but significant effect $(\mathrm{B}=0.18, \mathrm{p}=0.06)$ on the cognitive learning dimension. This confirms hypothesis H1a: PSM is positively associated with public leaders' cognitive learning orientation. As regards cognitive learning, none of the other independent variables play a significant role. Second, the results show that 'attachment to public service and values' (APS/CPV) is significantly associated with behavioral learning ( $\mathrm{B}=0.22, \mathrm{p}=0.02$ ). This confirms hypothesis $H 1 b$ : PSM is positively associated with behavioral learning. The results also show that experience as a mayor plays a negative role (if 'mayoral tenure' 1-2 years, $\mathrm{B}=-1.26, \mathrm{p}=0.007$; if 'mayoral tenure' $5-10$ years, $\mathrm{B}=-1.06$, $\mathrm{p}=0.007$; and if 'mayoral tenure' $>10$ years, $\mathrm{B}=-1.00, \mathrm{p}=0.006$ ) in that the longer a mayor has been in post the more reluctant they are to adjust the organization's culture. One explanation could be that, the longer a mayor has been working in a municipal administration, the more they become socialized to the organization's culture and identify with the organization's structure and procedures, making them less willing to change things.

Both of the political learning dimensions that came out of the principal component analysis were included in the regression analysis. First, the data indicate that the 'compassion and self-sacrifice' (COM/ SS) dimension of PSM has a positive effect on accountability-related learning $(\mathrm{B}=0.22, \mathrm{p}=0.02)$. We also see that 'crisis experience' has a significant positive relationship with political accountability $(\mathrm{B}=0.17$, $\mathrm{p}=0.01$ ), which indicates that the more crises a mayor has experienced in a municipality, the more highly they prioritize this type of political activities. It seems that, the more that mayors have dealt with crises in their municipality, the more they are aware of the importance of political processes such as blaming and framing, and the more conscious they are of the importance of the political accountability process. Second, the analysis showed that both the COM/SS and APS/CPV PSM dimensions were positively associated with learning in terms of improving external communication $(\mathrm{B}=0.21, \mathrm{p}=0.04 ; \mathrm{B}=0.22$, $\mathrm{p}=0.02$ ). To conclude, PSM is positively associated with an orientation towards both political learning dimensions, which means that, hypothesis $H 2$ has to be rejected. This finding seems to suggest that mayors also consider refining political processes in the immediate aftermath of a crisis as important for the public good (the organization and society) in the long run. Concentrating on purely political issues 
Table 5

OLS regressions of PSM and crisis-induced learning dimensions.

\begin{tabular}{|c|c|c|c|c|}
\hline Independent variables & Factor 1 behavioral learning & Factor 2 accountability & Factor 3 external communication & Factor 4 cognitive learning \\
\hline & B (s.e.) & B (s.e.) & B (s.e.) & B (s.e.) \\
\hline \multicolumn{5}{|l|}{ Public service motivation } \\
\hline Compassion and self-sacrifice (COM/SS) & $-0.08(0.09)$ & $0.22(0.09)^{* * *}$ & $0.21(0.09)^{* *}$ & $0.18(0.09)^{*}$ \\
\hline Attachment to public service and values (APS/CPV) & $0.22(0.10)^{k / k}$ & $-0.11(0.10)$ & $0.20(0.10)^{* * t}$ & $-0.01(0.10)$ \\
\hline \multicolumn{5}{|l|}{ Control variables } \\
\hline Gender $=$ male & $0.04(0.25)$ & $0.19(0.26)$ & $-0.07(0.25)$ & $-0.36(0.27)$ \\
\hline Age & $-0.00(0.01)$ & $0.02(0.01)^{*}$ & $-0.01(0.01)$ & $0.02(0.01)$ \\
\hline \multicolumn{5}{|l|}{ Mayoral tenure ${ }^{a}$} \\
\hline $1-2$ years & $-1.26(0.46)^{* * * *}$ & $-0.67(0.47)$ & $-0.47(0.46)$ & $-0.47(0.49)$ \\
\hline $2-5$ years & $-0.61(0.35)$ & $-0.36(0.36)$ & $0.08(0.35)$ & $-0.15(0.37)$ \\
\hline $5-10$ years & $-1.06(0.39)^{k * k *}$ & $-0.60(0.40)$ & $0.23(0.39)$ & $-0.38(0.41)$ \\
\hline$>10$ years & $-1.00(0.36)^{k * * * *}$ & $-0.70(0.36)^{*}$ & $0.43(0.36)$ & $-0.17(0.38)$ \\
\hline \multicolumn{5}{|l|}{ Political affiliation ${ }^{b}$} \\
\hline Christian democrat & $0.56(0.28)^{k . * k}$ & $0.15(0.28)$ & $-0.01(0.28)$ & $-0.07(0.29)$ \\
\hline Liberal & $0.43(0.28)$ & $0.18(0.28)$ & $0.13(0.28)$ & $-0.01(0.29)$ \\
\hline Social democrat & $-0.01(0.30)$ & $0.00(0.30)$ & $0.01(0.30)$ & $0.20(0.31)$ \\
\hline Crisis experience (number) & $0.02(0.06)$ & $0.17(0.06)^{k * k}$ & $0.03(0.06)$ & $0.05(0.07)$ \\
\hline \multicolumn{5}{|l|}{ Municipality population size ${ }^{c}$} \\
\hline $15,000-25,000$ & $-0.06(0.29)$ & $-0.17(0.30)$ & $0.26(0.29)$ & $-0.10(0.31)$ \\
\hline $25,000-50,000$ & $0.26(0.27)$ & $-0.24(0.28)$ & $-0.33(0.27)$ & $-0.26(0.29)$ \\
\hline $50,000-100,000$ & $0.12(0.38)$ & $-0.47(0.38)$ & $0.23(0.38)$ & $-0.25(0.40)$ \\
\hline$>100,000$ inhabitants & $-0.09(0.54)$ & $-0.18(0.55)$ & $-0.18(0.54)$ & $-0.10(0.58)$ \\
\hline Constant & $0.33(0.77)$ & $-1.08(0.78)$ & $0.49(0.77)$ & $-0.35(0.81)$ \\
\hline $\mathrm{R}^{2}$ & 0.19 & 0.15 & 0.17 & 0.09 \\
\hline $\mathrm{N}$ & 135 & 135 & 135 & 135 \\
\hline
\end{tabular}

Unstandardized Coefficients.

" $\mathrm{p}<0.1,{ }^{* * *} \mathrm{p}<0.05,{ }^{* * *} \mathrm{p}<0.01$.

a Reference category $<1$ year experience.

b Reference category $=$ other affiliation.

c Reference category $=<15,000$.

such as adapting the political strategy, allocating blame, dealing with external party interests, and limiting reputational damage, might be viewed as serving public values and the well-being of society similar to efforts into acquiring knowledge and changing the organization's culture (i.e., instrumental learning).

\section{Conclusions and discussion}

This study has explored public leaders' organizational learning orientations in the wake of a crisis, and the relationship between this and their public service motivation (PSM). The aim was to establish systematic empirical evidence on crisis leadership in connection with crisis-induced learning and to refine the operationalization of the dimensions of crisis-induced learning (Smith and Elliot, 2007; Dekker and Hansén, 2004). We investigated elements of crisis-induced learning that were derived from the crisis management literature and previous surveys in the field of organizational learning, and further applied the public service motivation measurement scale of Kim et al. (2013), in a survey study among Dutch mayors.

Our study revealed 'cognitive', 'behavioral', 'accountability' and 'external communication' dimensions of public leaders' crisis-induced learning orientations and two dimensions of PSM: 'attachment to public service and values' and 'compassion and self-sacrifice', rather than the four identified by Kim et al. (2013). We found that mayors with a stronger PSM give higher priority to both instrumental (cognitive and behavioral) learning and political learning (accountability and external communication) than those with a weaker PSM in the wake of a crisis. This finding confirms our hypothesis that a mayor's PSM is positively associated with their orientation towards instrumental learning, but rejects our hypothesis that a mayor's PSM is negatively associated with their orientation towards political learning. Further, we found that mayoral experience with previous crisis situations is positively associated with accountability-related political learning. Mayoral tenure is, however, negatively associated with behavioral learning following a crisis.

This study has several implications. First, the more refined operationalization of crisis-induced learning provides an important step towards the establishment of a systematic measurement instrument for crisis-induced learning. One of the challenges in this study was related to the validity of conceptualizations of organizational learning, which has been defined and measured in many different ways (Fiol and Lyles, 1985; Crossan et al., 1999; Dekker and Hansén, 2004, p. 141). Moreover, despite crisis-induced learning being acknowledged as a focal issue in the managing of crises, crisis management research lacks a clear definition and operationalization of what learning in the wake of a crisis entails. Here, the four dimensions that we identified require further rigorous testing in new contexts - in terms of agents, organizations, and institutional settings - to build confidence in the measurement instrument.

This study further contributes to the literature by addressing and specifying the political dimension of crisis-induced organizational learning in addition to a common 'technical' approach to the process (e.g., Choularton, 2001; Vastveit et al., 2015; Silva et al., 2017). Crisisinduced learning inherently differs in several respects from organizational learning in more 'regular' times. Our findings indicate that crisisinduced lessons are characteristically rooted in specific events and involve adjustments in political activities related to accountability and communication, such as attributing responsibilities, monitoring public opinion, balancing parties' interests, and communicating to the media (see Boin et al., 2016; Seeger et al., 2003). In contrast, aspects of learning that entail continuous long-term organizational processes, or require calm periods, such as learning by trial-and-error and experimentation, are not, or only to a lesser extent, applicable to crisis-induced learning (see Marsick and Watkins, 2003; Goh and Richards, 
1997; Chiva et al., 2007; Garvin et al., 2008). The finding that public leaders who are oriented towards political accountability also tend to promote quick and procedural changes in an organization was unexpected, and suggests that leaders consider implementing procedural, less-structural, changes in response to political pressures. We recommend further research on the role of specific political learning processes (see also May, 1992; Birkland, 2006).

Moreover, the present study connects crisis-induced learning to public leadership theory. The analysis shows that public leaders' approach to learning after a crisis can be explained by a systematic variation in PSM, rather than by idiosyncratic personality traits. If we consider PSM to be an orientation towards doing good for society, we see that public leaders with a high PSM are more oriented towards not only instrumental learning but, perhaps surprisingly, also towards political learning. One interpretation is that such leaders not only consider instrumental learning but also political learning as being important for the organization and for the wider society in the long run. Political efforts such as adapting the political strategy, allocating blame, and limiting reputational damage might similarly benefit the public interest as efforts in acquiring knowledge and improving the organization's culture. This suggests that, in the context of a crisis, both kinds of organizational learning are experienced as important in building resilience. The results of this study further stress the significance of experience as a factor in crisis-induced learning (Deverell, 2010). Finally, this study shows that it is appropriate to apply the PSM concept (Perry and Hondeghem, 2008), and the measurement scale proposed by Kim et al. (2013) specifically, to public office holders and maybe even to political leaders.

The critical findings in the analysis may provide support for education, trainings, and designing of simulations specifically addressing the needs of mayors in the response to crises. This might enhance the crisis preparedness of municipalities. Despite the limitations of our research, which is based on cross-sectional data derived from a specific group of respondents, the study does suggest that linking crisis-induced learning to actors' motivations is a valid avenue for further research.

\section{Acknowledgements}

This research was financially supported by the 'Double Bind' research program of the Netherlands Organization for Scientific Research (grant no. 452-10-001). We would like to thank Eline Burgers and Steffen Zabler for their support at different stages of the research process.

\section{References}

Andersen, L., Kjeldsen, A., 2013. Public service motivation, user orientation, and job satisfaction: a question of employment sector? Int. Publ. Manage. J. 16 (2), 252-274. Andersen, L., Serritzlew, S., 2012. Does public service motivation affect the behaviour of professionals? Int. J. Publ. Admin. 35 (1), 19-29.

Argyris, C., Schön, D.A., 1978. Organizational Learning: a Theory of Action Perspective. Addison-Wesley, Reading, MA.

Birkland, T.A., 2006. Lessons of Disaster. Policy Change After Catastrophic Events. Georgetown University Press, Washington.

Boin, A., 't Hart, P., 2003. Public leadership in times of crisis: mission impossible? Public Admini. Rev. 63 (5), 544-553.

Boin, A., 't Hart, P., McConnell, A., 2009. Crisis exploitation: political and policy impacts of framing contests. J. Eur. Publ. Policy 16 (1), 81-106.

Boin, A., 't Hart, P., Stern, E., Sundelius, B., 2016. The Politics of Crisis Management Publicleadership Under Pressure, second ed. Cambridge University Press, Cambridge.

Boin, A., McConnell, A., 't Hart, P. (Eds.), 2008. Governing After Crisis. The Politics of Investigation, Accountability and Learning. Cambridge University Press, Cambridge.

Broekema, W., 2016. Crisis-induced learning and issue politicization in the EU: the Braer, Sea Empress, Erika, and Prestige oil spill disasters. Publ. Admini. 94 (2), 381-398.

Broekema, W., Van Kleef, D., Steen, T., 2017. What factors drive organizational learning from crises? insights from the Dutch food safety services' response to four veterinary crises. J. Conting. Crisis Manage. 25 (4), 326-340.

Brändström, A., Kuipers, S., 2003. From 'normal incidents' to political crises: understanding the selective politicization of policy failures. Govern. Oppos. 38 (3), 279-305.

Brewer, G.A., Selden, S.C., 1998. Whistle blowers in the federal civic service: new evidence of the public service ethic. J. Publ. Admini. Res. Theory 8 (3), 413-439.

Capoccia, G., Kelemen, R.D., 2007. The study of critical junctures. Theory, narrative, andcounterfactuals in historical institutionalism. World Politics 59 (3), 341-369.

Carley, K.M., Harrald, J.R., 1997. Organizational learning under fire: theory and practice. Am. Behav. Sci. 40 (3), 310-332.

CBS [Statistics Netherlands] (2017). Statline. < http://statline.cbs.nl > . (accessed June 22nd 2017).

Chiva, R., Alegre, J., Lapiedra, R., 2007. Measuring organizational learning capability among the workforce. Int. J. Manpower 28 (3), 224-242.

Choularton, R., 2001. Complex learning: organizational learning from disasters. Saf. Sci. 39 (1-2), 61-70.

Christensen, T., Lægreid, P., Rykkja, L.H., 2016. Organizing for crisis management: building governance capacity and legitimacy. Publ. Admini. Rev. 76 (6), 887-897.

Comfort, L.K., Okada, A., 2013. Emergent leadership in extreme events: a knowledge commons for sustainable communities. Int. Rev. Publ. Admini. 18 (1), 61-77.

Coombs, W.T., 2006. The protective powers of crisis response strategies: managing reputational assets during a crisis. J. Promot. Manage. 12 (3), 241-260.

Coombs, W.T., 2012. Ongoing crisis communication. Planning, managing, and responding, third ed. Sage, Thousand Oaks, CA.

Coombs, T., Holladay, S.J., 2002. Helping crisis managers protect reputational assets. Manage. Commun. Quart. 16 (2), 165-186.

Comfort, L.K., Okada, A., 2013. Emergent leadership in extreme events: a knowledge commons for sustainable communities. Int. Rev. Publ. Admini. 18 (1), 61-77.

Crossan, M.M., Lane, H.W., White, R.E., 1999. An organizational learning framework: from intuition to institution. Acad. Manage. Rev. 24 (3), 522-537.

De Vries, B., 2016. Burgemeesters in crisistijd. De invloed van context en persoonlijkheid op het leiderschap van de opperbevelhebber. Leiden University, Leiden.

Dekker, S., Hansén, D., 2004. Learning under pressure: the effects of politicization onorganizational learning in public bureaucracies. J. Publ. Admin. Res. Theory 14 (2), 211-230.

Deverell, E., 2009. Crises as learning triggers: exploring a conceptual framework of crisisinduced learning. J. Conting. Crisis Manage. 17 (3), 179-188.

Deverell, E., 2010. Flexibility and rigidity in crisis management and learning at Swedish public organizations. Publ. Manage. Rev. 12 (5), 679-700.

Downe, J., Hartley, J., Rashman, L., 2004. Evaluating the extent of inter-organizational learning and change in local authorities through the english beacon council scheme. Publ. Manage. Rev. 6 (4), 531-554.

Elliott, D., 2009. The failure of organizational learning from crisis - a matter of life and death? J. Conting. Crisis Manage. 17 (3), 157-168.

Fiol, C.M., Lyles, M.A., 1985. Organizational learning. Acad. Manage. Rev. 10 (4), 803-813.

Garvin, D.A., Edmondson, A.C., Gino, F., 2008. Is yours a learning organization? Harvard Business Rev. 89, 1-11.

Gilpin, D.R., Murphy, P.J., 2008. Crisis Management in a Complex World. Oxford University Press, Oxford.

Goh, S., Richards, G., 1997. Benchmarking the learning capability of organizations. Eur. Manage. J. 15 (5), 575-583.

Hadley, C.N., Pittinsky, T.L., Sommer, S.A., Zhu, W., 2011. Measuring the efficacy of leaders toassess information and make decisions in a crisis: the C-LEAD scale. The Leadership Quarterly 22, 633-648.

Hale, J.E., Hale, D.P., Dulek, R.E., 2006. Decision processes during crisis responses: an exploratory investigation. J. Manage. Issues VXIII (3), 301-320.

Huber, G.P., 1991. Organizational learning: the contributing processes and the literatures. Organ. Sci. 2 (1), 88-115.

Jensen, U.T., Andersen, L.B., 2015. Public service motivation, user orientation, and prescription behaviour: doing good for society or for the individual user? Publ. Admin. 93 (3), 753-768.

Jong, W., Dückers, M.L.A., Van der Velden, P.G., 2016. Leadership of mayors and governors during crises: a systematic review on tasks and effectiveness. J. Conting. Crisis Manage. 24 (1), 46-58.

Kapucu, N., 2006. Interagency communication networks during emergencies. Am. Rev. Publ. Admin. 36 (2), 207-225.

Kim, S., Vandenabeele, W., 2010. A strategy for building public service motivation research internationally. Publ. Admin. Rev. 70 (5), 701-709.

Kim, S., Vandenabeele, W., Wright, B.E., Bøgh Andersen, L., Cerase, F.P., Christensen, R.K., Desmarais, C., Koumenta, M., Leisink, P., Liu, L., Palidauskaite, J., Pedersen, L.H., Perry, J.L., Ritz, A., Taylor, J., De Vivo, P., 2013. Investigating the structure and meaning of public service motivation across populations: developing an international instrument and addressing issues of measurement invariance. J. Publ. Admin. Res. Theory 23 (1), 79-102.

Kingdon, J.W., 2003. Agendas, Alternatives, and Public Policies, second ed. Longman, New York

Liu, B., Du, L., Wen, H., Fan, B., 2012. Public service motivation of public- versus privatesector employees in a chinese context. Soc. Behav. Personal. 40 (9), 1409-1418.

Marsick, V.J., Watkins, K.E., 2003. Demonstrating the value of an organization's learning culture: the dimensions of the Learning Organization Questionnaire. Adv. Develop. Human Resources 5 (2), 132-151.

May, P.J., 1992. Policy learning and failure. J. Publ. Policy 12 (4), 331-354.

Min. BZK [Ministry of the Interior and Kingdom Relations], 2014. Staat van het Bestuur. Rijkswijk: Quantes.

Min. VenJ [Ministry of Security and Justice], 2013. Wet veiligheidsregio's. Den Haag: Min. VenJ.

Moynihan, D.P., 2008. Learning under uncertainty: networks in crisis management. Publ. Admin. Rev. 68 (2), 350-361.

Municipal Act [Gemeentewet], 1992. Identification no. BWBR0005416.

Nederhof, A.J., 1985. Methods of coping with social desirability bias: a review. Eur. J. 
Soc. Psychol. 15 (3), 263-280.

NGB [Dutch Association of Mayors], 2013. Handreiking. Bestuurlijke aandachtspunten bij crises. Den Haag: NGB.

Olson, R.S., 2000. Toward a politics of disaster: losses, values, agendas, and blame. Int. J. Mass Emerg. Disasters 18 (2), 265-287.

Perry, J.L., 1996. Measuring public service motivation: an assessment of construct reliability and validity. J. Publ. Admin. Res. Theory 6 (1), 5-22.

Perry, J.L., Hondeghem, A., 2008. Building theory and empirical evidence about public service motivation. Int. Publ. Manage. J. 11 (1), 3-12.

Pressman, J.L., Wildavsky, A., 1984. Implementation. How Great Expectations in Washington are Dashed in Oakland. California University Press, Berkely, CA.

Resodihardjo, S.L., 2006. Wielding a double-edged sword: the use of inquiries at times of crisis. J. Conting. Crisis Manage. 14 (4), 199-206.

Rosenthal, U., Boin, A.R., Comfort, L.K., 2001. Managing Crises. Threats, Dilemmas, Opportunities. Charles C Thomas, Springfield.

Roux-Dufort, C., 2000. Why organizations don't learn from crises: the perverse power ofnormalization. Rev. Business 21 (3), 25-30.

Schiffino, N., Taskin, L., Donis, C., Raone, J., 2016. Post-crisis learning in public agencies: what do we learn from both actors and institutions? Policy Studies 38 (1), 59-75.

Schott, C., van Kleef, D., Steen, T., 2018. The combined impact of professional role identity and public service motivation on decision-making in dilemma situations. Int. Rev. Admin. Sci. 84 (1), 21-41.

Scholtens, A., 2008. Controlled collaboration in disaster and crisis management in the Netherlands, history and practice of an overestimated and underestimated concept. J. Conting. Crisis Manage. 16 (4), 195-207.

Seeger, M.W., Sellnow, T.L., Ulmer, R.R., 2003. Communication and organizational crisis.
Westport. Quorum Press, CT.

Senge, P.M., 1990. The Fifth Discipline. The Art and Practice of the Learning Organization. Currency Doubleday, New York, NY.

Silva, S.A., Carvalho, H., Oliveira, M.J., Fialho, T., Soares, C.G., Jacinto, C., 2017 Organizational practices for learning with work accidents throughout their information cycle. Saf. Sci. 99 (A), 102-114.

Smith, D., Elliott, D., 2007. Exploring the barriers to learning from crisis: organizational learning and crisis. Manage. Learn. 38 (5), 519-538.

Stern, E., 1997. Crisis and learning: a conceptual balance sheet. J. Conting. Crisis Manage. 5 (2), 69-86.

Taylor, J., 2010. Public service motivation, civic attitudes and actions of public, nonprofit and private sector employees. Publ. Admin. 88 (4), 1083-1098.

Toft, B., Reynolds, S., 1994. Learning from Disasters. A Management Approach. Butterworth-Heinemann, Oxford.

Torenvlied, R., 2000. Political Decisions and Agency Performances. Kluwer Academic Publishers, London.

Turner, B.A., 1976. The organizational and interorganizational development of disasters. Adm. Sci. Q. 21 (3), 378-397.

Van Wart, K., Kapucu, N., 2011. Crisis management competencies. The case of emergency managers in the USA. Publ. Manage. Rev. 13 (4), 489-511.

Vastveit, K.R., Boin, A., Njå, O., 2015. Learning from incidents: practices at a Scandinavian refinery. Saf. Sci. 79 (A), 80-87.

Weick, K.E., 1995. Sensemaking in Organizations. Sage, Thousand Oaks, CA.

Weick, K.E., Sutcliffe, K.M., 2001. Managing the Unexpected: Assured High Performance in an Age of Complexity. Jossey-Bass, San Francisco. 